\title{
Cardiovascular Risk Reduction in Women Following Hypertensive Disorders of Pregnancy - a Prospective, Randomised, Controlled Interventional Study
}

\section{Kardiovaskuläre Risikoreduktion bei Frauen mit Zustand nach hypertensiven Schwangerschaftserkrankungen - eine prospektive, randomisierte, kontrollierte Interventionsstudie}

\section{(ㄷ) (1)}

Authors

Marcus Riemer ${ }^{1,2}$, Stephan Schulze ${ }^{3}$, Lisa Wagner ${ }^{1}$, Manon Richter ${ }^{4}$, Gertrud Ayerle ${ }^{5}$, Andreas Simm ${ }^{6}$, Sven Seeger ${ }^{2}$, René Schwesig ${ }^{3}$, Michael Tchirikov ${ }^{1}$, Gregor Seliger ${ }^{1}$

Affiliations

1 Universitätsklinik und Poliklinik für Geburtshilfe und Pränatalmedizin Halle, Martin-Luther-Universität HalleWittenberg, Halle, Germany

2 Klinik für Geburtshilfe, Krankenhaus St. Elisabeth und St. Barbara Halle, Halle, Germany

3 Department für Orthopädie, Unfall- und Wiederherstellungschirurgie, Martin-Luther-Universität Halle-Wittenberg, Halle, Germany

4 Institut für Leistungsdiagnostik und Gesundheitsförderung, Martin-Luther-Universität Halle-Wittenberg, Halle, Germany

5 Institut für Gesundheits- und Pflegewissenschaft, MartinLuther-Universität Halle-Wittenberg, Halle, Germany

6 Universitätsklinik für Herz- und Thoraxchirurgie Halle, Martin-Luther-Universität Halle-Wittenberg, Halle, Germany

Key words

preeclampsia, HELLP syndrome, arterial stiffness, pulse wave velocity, cardiovascular risk

Schlüsselwörter

Präeklampsie, HELLP-Syndrom, arterielle Steifigkeit,

Pulswellengeschwindigkeit, kardiovaskuläres Risiko
received
6. 7. 2020

accepted after revision

31. 12.2020

Bibliography

Geburtsh Frauenheilk 2021; 81: 966-978

DOI 10.1055/a-1345-8733

ISSN 0016-5751 (c) 2021. The Author(s).

This is an open access article published by Thieme under the terms of the Creative Commons Attribution-NonDerivative-NonCommercial-License, permitting copying and reproduction so long as the original work is given appropriate credit. Contents may not be used for commercial purposes, or adapted, remixed, transformed or built upon. (https://creativecommons.org/licenses/by-nc-nd/4.0/)

Georg Thieme Verlag KG, Rüdigerstraße 14,

70469 Stuttgart, Germany

Correspondence

Dr. Marcus Riemer

Martin-Luther-Universität Halle-Wittenberg,

Universitätsklinik für Geburtshilfe und Pränatalmedizin Halle

Ernst Grube Straße 40, 06120 Halle, Germany

marcus.riemer@outlook.com

$\circledast$

Deutsche Version unter:

https://doi.org/10.1055/a-1345-8733

\section{ABSTRACT}

Background Women have a markedly increased lifetime risk for cardiovascular morbidity and mortality following hypertensive disorders of pregnancy. Arterial stiffness is regarded as a target parameter for reducing cardiovascular risk and can be modified by lifestyle changes.

Methods In a prospective, randomised, controlled interventional study, starting 6 weeks postpartum, the effect of nutritional intervention combined with an intensive 6-month cardiovascular exercise programme on arterial stiffness was investigated by means of pulse wave velocity (PWV) in 38 women with severe hypertensive disorder of pregnancy (preeclampsia with or without pre-existing hypertension and/or HELLP syndrome). A reference group was formed with postpartum women without pregnancy complications or known cardiovascular risk and the arterial stiffness was studied by means of PWV at the time of delivery. The PWV was measured 
in the intervention and control groups within a week after delivery and after 32 weeks ( 6 weeks +6 months). A feasibility analysis was performed in addition.

Results 29 of 38 women with severe hypertensive disorder of pregnancy and 38 postpartum women in the reference group were included in the analysis (intervention group $n=14$; control group $n=15$; reference group $n=38$ ). Adherence to a) the nutritional counselling and b) the intensive cardiovascular exercise programme was $73 \%$ and $79 \%$ respectively. A clinically significant difference $(\mathrm{d}=0.65)$ in pulse wave velocity between the intervention and control groups was found after 6 months $(6.36 \pm 0.76$ vs. $7.33 \pm 2.25 \mathrm{~m} / \mathrm{s}$; group $\times$ time: $p=0.632$ ). The PWV of the intervention group corresponded to that of the reference group at the end of the study $(6.36 \pm 0.76 \mathrm{~m} / \mathrm{s}$ vs. $6.5 \pm 0.70 ; d=0.19)$, while the results in the control group differed markedly from this $(7.33 \pm 2.25 \mathrm{~m} / \mathrm{s} ; \mathrm{d}=0.56)$.

Conclusion The study documents the feasibility of lifestyle intervention with physical exercise after delivery (starting 6 weeks postpartum). The intervention showed a significant clinical effect by reducing arterial stiffness to the level of the reference group. Before this intervention can be included in the standard of care and prevention, follow-up studies must confirm these results and the medium-term effects on cardiovascular risk.

\section{ZUSAMMENFASSUNG}

Hintergrund Frauen mit Z.n. hypertensiven Schwangerschaftserkrankungen haben ein deutlich erhöhtes Lebenszeitrisiko für kardiovaskuläre Morbidität und Mortalität. Die arterielle Steifigkeit gilt dabei als ein Zielparameter für die Reduktion des kardiovaskulären Risikos und kann durch Lebensstilveränderungen modifiziert werden.

Methoden Im Rahmen einer prospektiven, randomisierten, kontrollierten Interventionsstudie wurde beginnend 6 Wochen post partum der Effekt einer Ernährungsintervention kombiniert mit einem 6-monatigen intensiven Herz-Kreislauf-Trainingsprogramm auf die arterielle Steifigkeit mittels Pulswellengeschwindigkeit (PWV) bei 38 Frauen mit schwerer hypertensiver Schwangerschaftserkrankung ([Pfropf-]Präeklampsie und/oder HELLP-Syndrom) untersucht. Ebenso wurde als Referenz eine Gruppe mit postpartalen Frauen ohne Schwangerschaftskomplikationen oder bekanntem kardiovaskulären Risiko gebildet und die arterielle Steifigkeit mittels PWV am Entbindungszeitpunkt untersucht. Die PWV wurde in der Interventions- und Kontrollgruppe innerhalb einer Woche nach Entbindung sowie nach 32 Wochen (6 Wochen + 6 Monate) bestimmt. Zusätzlich wurde eine Machbarkeitsanalyse durchgeführt.

Ergebnisse 29 von 38 Frauen mit schwerer hypertensiver Schwangerschaftserkrankung sowie 38 postpartale Frauen der Referenzgruppe wurden in die Analyse eingeschlossen (Interventionsgruppe $n=14$; Kontrollgruppe $n=15$; Referenzgruppe $n=38$ ). Die Adhärenz zur a) Ernährungsberatung und b) dem intensiven Herz-Kreislauf-Trainingsprogramm betrug 73\% bzw. 79\%. Es zeigte sich ein klinisch relevanter Unterschied $(d=0,65)$ in der Pulswellengeschwindigkeit nach 6 Monaten zwischen der Interventions- und Kontrollgruppe $(6,36 \pm 0,76$ vs. $7,33 \pm 2,25 \mathrm{~m} / \mathrm{s}$; Gruppe $\times$ Zeit: $p=0,632)$. Die PWV der Interventionsgruppe entsprach am Studienende der Referenzgruppe $(6,36 \pm 0,76 \mathrm{~m} / \mathrm{s}$ vs. $6,5 \pm 0,70$; $d=0,19)$, währenddessen sich die Werte der Kontrollgruppe deutlich von selbiger unterschieden $(7,33 \pm 2,25 \mathrm{~m} / \mathrm{s}$; $d=0,56)$.

Schlussfolgerung Die Studie dokumentiert die Machbarkeit einer Lifestyleintervention mit körperlichem Training nach dem Wochenbett (Start 6 Wochen post partum). Dabei zeigte die Intervention einen relevanten klinischen Effekt durch Senkung der arteriellen Steifigkeit auf das Niveau der Referenzgruppe. Bevor diese Intervention in den Versorgungs- und Präventionsstandard übernommen werden kann, müssen Follow-up-Studien diese Ergebnisse und mittelfristige Effekte auf das kardiovaskuläre Risiko bestätigen.

\section{Introduction}

Up to $8 \%$ of pregnant women suffer from a hypertensive disorder of pregnancy such as preeclampsia, and the incidence is increasing $[1,2]$. Preeclampsia is regarded as the leading cause of maternal death in industrialised nations [3-5]. Apart from the shortterm morbidity, preeclampsia increases the long-term cardiovascular risk [6]. Women who have had preeclampsia suffer cardiovascular and cerebrovascular events such as heart attack, heart failure, stroke and terminal kidney failure more often and earlier [6-9]. Cardiovascular diseases, in particular, have been accepted for decades as the leading cause of death globally independent of sex [10]. In Germany alone cardiovascular diseases were the main cause of death in 2015, with 365000 deaths (39\% of all deaths) and the disease costs were 46.4 billion Euro (13\% of total costs) $[11,12]$. Consequently, not only the immediate treatment of hypertensive disorders of pregnancy [13], but also the (secondary) prevention of cardiovascular disease following hypertensive disor- ders of pregnancy is one of the major challenges of innovative medicine in the 21st century.

Regular physical activity can have a positive effect on the lifetime risk for cardiovascular disease, including after preeclampsia $[14,15]$. Both the American Heart Association and the European Society of Cardiology proclaim in their guidelines at least $75 \mathrm{~min}$ of intensive or 150 min of moderately intensive, aerobic exercise weekly - regardless of pre-existing disease or risk factors - as cardiovascular prevention for the entire population [16,17].

Apart from regular physical exercise in the form of active sport, a varied and regular diet low in carbohydrate and salt and with reduced saturated fatty acids and high in protein is essential [1821].

Pregnancy can also be regarded in otherwise clinically healthy women as a "window to future health" [22-25]. In this connection, therefore, the postpartum assessment of cardiovascular health risks and secondary and tertiary preventive treatment are of great importance. 
Arterial stiffness is an important biomarker for predicting cardiovascular events. Vascular stiffness and thus vascular age increase due to structural changes in the vessel walls with endothelial dysfunction. Because of the increase in velocity of the pulse wave generated in systole, this leads to earlier reflection of this in the periphery and thus to an increase in cardiac afterload. Arterial stiffness is measured non-invasively by means of pulse wave velocity.

Sanders et al. [26], referring in their comments to Zieman et al. [27], conclude that vascular stiffness can be used as a treatment goal even in a young population with cardiovascular risks but that studies must show evidence of an improvement in the results due to treatment-related changes [26, 27].

Arterial stiffness has become an interesting target and the focus of scientific interest because it is measured non-invasively by aortic pulse wave velocity (aPWV) and it is readily available and reproducible including in pregnant women and in the puerperium [28]. Kaihura et al. [29] showed that arterial stiffness is significantly increased at the time of delivery in women with preeclampsia compared with healthy pregnant women. In both the short and long term, arterial stiffness and therefore biological vascular age remain markedly elevated in the group of women who have had preeclampsia $[29,30]$. Scholten et al. [14] presented data from an exercise intervention for 12 weeks in women following preeclampsia 6-12 months postpartum. They found an improvement in metabolic syndrome factors in the post-preeclampsia and control group but no normalisation of the vascular variables in the women who had had preeclampsia [14]. Thus, both the intervention duration and the timing of the intervention after preeclampsia appear to influence the success of vascular normalisation.

The aim of this study was the reduction of arterial stiffness after the conclusion of the puerperium by means of a complex intervention consisting of basic aerobic endurance exercise and nutritional counselling in women with severe hypertensive disorder of pregnancy (preeclampsia with or without pre-existing hypertension and/or HELLP syndrome). In addition, the acceptance, motivation and adherence of the patients with regard to the planned complex, interdisciplinary, interprofessional and crosssector interventions were examined in feasibility analyses.

\section{Methods}

\section{Recruitment}

The study was conducted at the University Department of Obstetrics and Prenatal Medicine Halle, (Saale) and at St. Elisabeth and St. Barbara Hospital Halle (Saale) from 2016 to 2019 (ClinicalTrials.gov Identifier: NCT02754778). Recruitment took place over 24 months.

Potential subjects were screened for participation in the study in accordance with the inclusion and exclusion criteria within 7 days after delivery if they had a severe hypertensive disorder of pregnancy (preeclampsia with or without pre-existing hypertension and/or HELLP syndrome) and were invited to take part if the inclusion and exclusion criteria were met and adequate communication was possible (acquisition). After consenting to take part in the study, the first study visit took place with randomisation to the

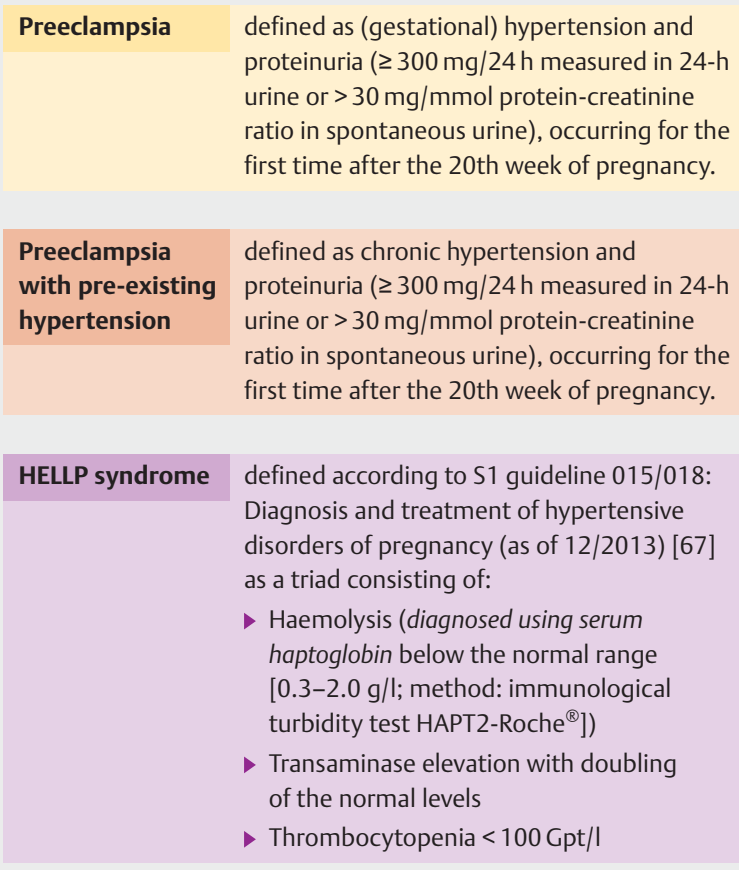
proteinuria ( $\geq 300 \mathrm{mg} / 24 \mathrm{~h}$ measured in $24-\mathrm{h}$ urine or $>30 \mathrm{mg} / \mathrm{mmol}$ protein-creatinine ratio in spontaneous urine), occurring for the first time after the 20th week of pregnancy.

Preeclampsia defined as chronic hypertension and with pre-existing proteinuria $(\geq 300 \mathrm{mg} / 24 \mathrm{~h}$ measured in $24-\mathrm{h}$ hypertension urine or $>30 \mathrm{mg} / \mathrm{mmol}$ protein-creatinine ratio in spontaneous urine), occurring for the first time after the 20th week of pregnancy.

\section{HELLP syndrome defined according to S1 guideline 015/018: Diagnosis and treatment of hypertensive disorders of pregnancy (as of 12/2013) [67] as a triad consisting of: \\ - Haemolysis (diagnosed using serum haptoglobin below the normal range [0.3-2.0 g/l; method: immunological turbidity test HAPT2-Roche ${ }^{\circledR}$ ]) \\ - Transaminase elevation with doubling of the normal levels \\ - Thrombocytopenia < $100 \mathrm{Gpt} / \mathrm{I}$}

- Fig. 1 Definition criteria according to S1 guideline 015/018: Diagnosis and treatment of hypertensive disorders of pregnancy (as of 12/2013) [45].

intervention and control group in the ratio $1: 1$ using a web-based random generator (recruitment).

The inclusion and exclusion criteria and previous findings, especially with regard to cardiovascular disease were established from the medical history, review of the maternity log and, if necessary, obtaining previous external reports in the event of uncertainties.

\section{Inclusion criteria}

Women over 18 years with evidence of preeclampsia with or without pre-existing hypertension and/or HELLP syndrome ( $\bullet$ Fig. 1) on the day of delivery and up to 7 days postpartum after full differential diagnosis and according to the definition of the 2016 S1 guideline "Diagnosis and treatment of hypertensive disorders of pregnancy" and who had capacity to give consent were included $[31,32]$.

\section{Exclusion criteria}

Women were excluded who had heart failure > NYHA II, peripheral arterial disease (regardless of stage) or a serious neurological or orthopaedic disease postpartum, which would have made exercise training on the bicycle ergometer impossible. Women whose newborn or premature baby required intensive care at home and who could not have been expected to make the journey to the weekly exercise session were also excluded. 


\section{Discontinuation criteria}

If any of the points listed in the exclusion criteria appeared only in the aerobic basic endurance exercise, these subjects had to drop out of the study.

\section{Internal medicine check-up}

The subjects in the intervention group also had a medical checkup 5 weeks postpartum ( \pm 7 days) to obtain independent medical approval for the exercise intervention.

\section{Reference group of healthy women (inclusion/exclusion criteria)}

In the participating hospitals, the same number of women without a history or diagnosis of pregnancy complications and without known previous cardiovascular disease, who were legally of age and capable of giving consent and when the baby's course was uncomplicated - regardless of case number estimation - were recruited for the study as a reference group for aortic pulse wave velocity measurement up to 7 days after delivery (reference group recruitment target: 38 women).

\section{Measurement of pulse wave velocity}

The cuff-based Vicorder ${ }^{\circledR}$ (SMT Medical, Würzburg, Germany) was used to measure the aortic pulse wave velocity as the gold standard for determining arterial stiffness. This has already been validated repeatedly in studies against alternative measurement methods such as tonometry and magnetic resonance imaging [33-36]. The measurements were done in a standardised setting in the patient's air-conditioned room in the respective hospital (room temperature $22-25^{\circ} \mathrm{C}$, in supine position, after resting for 10 min, upper body elevated $30^{\circ}$ ). At the patient's bedside, the measurement setting was adjusted to be equivalent to that used for the Vicorder validation study [37]. Comparable settings were also used in studies elsewhere of non-invasive measurement of pulse wave velocity (tonometric, oscillometric), e.g., in children, simultaneously in MRI and in intensive care units and during angiological interventions in the operating theatre [38-42]. If the baby had not been transferred to the neonatal ICU but was in the room with the patient, it was given into the care of the ward nurse while the measurements were performed. A $10 \mathrm{~cm}$ wide BP cuff was then applied around the right thigh to measure the femoral pulse and a narrow $3 \mathrm{~cm}$ cuff was placed around the neck at the level of the right carotid artery to measure this. The distance between the jugular fossa and the cranial edge of the cuff applied to the thigh was measured as recommended by the manufacturer. Unlike the usual use of the Vicorder a tape measure was not used but rather a pelvimeter so as to avoid an incorrect measurement of length due to the postpartum distension of the abdominal wall. Both cuffs were pumped up to $65 \mathrm{mmHg}$ and 2 high-quality measurement curves were recorded for 3 seconds simultaneously by means of a volume displacement, from which the aPWV was derived [43]. The measurement was repeated 3 times in succession and the mean of all 3 measurements was used for statistical analysis.

The pulse wave velocity was measured in the intervention and control group both on the day of inclusion in the study (time 1 [T1]) and after 32 weeks ( 6 weeks puerperium +6 months inter- vention period, time 2 [T2]) and at the start of the exercise intervention in the subjects of the intervention group ( $\bullet$ Fig. 2). In the reference group of healthy subjects, the measurement took place once on the day of inclusion in the study (T1).

In the intervention and control group the first measurement was done at the patient's bedside in the delivery ward and the second measurement and final measurement on an examination couch. Stressors that influence blood pressure and also the newborn babies were not present in the examination or patient's room during the measurement.

\section{Ergometry}

Following the analysis of vascular stiffness, exercise ergometry was performed in the sport science laboratory in a standardised setting on a bicycle ergometer (motion cycle 600 med, emotion Fitness, Hochspeyer, Germany). An exercise protocol based on the WHO protocol was used (initial workload 25 watts, increment 25 watts, stage duration $3 \mathrm{~min}$ ) at a specified frequency of $60-$ 65 revolutions/min. To generate a submaximal load, reaching a target heart rate of 150 beats/min was defined as stop criterion. The load stage at which this value was reached was completed and the performance was reduced to 25 watts in the subsequent active cool-down. Before the start of the test, at the end of each load stage and after a 2 and 4 minute recovery period, the lactate level in capillary blood was determined (drawn from the hyperaemised earlobe) and the heart rate was recorded (RS800 CX, Polar electro Oy, Kempele, Finland). The test results were analysed using Winlactat software (version 4.7; mesics $\mathrm{GmbH}$, Münster, Germany) and the individual lactate threshold (LT) of the lactate performance curve was determined as the limit of the performance generated mainly aerobically for controlling the load in the subsequent intervention phase [44].

\section{Exercise programme to increase aerobic basic endurance and general strength endurance}

During the 6-month intervention phase an exercise unit was performed once a week under laboratory conditions. The exercise consisted of a heart rate-controlled exercise unit on a bicycle ergometer, with the load parameters based on the lactate threshold test results. Starting with a load duration of $25 \mathrm{~min}$ at the heart rate at the LT (HR $\mathrm{LT}_{\mathrm{LT}}$; mean: 129 beats/min; min.: 121 beats/min; max.: 137 beats/min) the load duration in the intervention period was gradually increased to 50 min within 14 weeks. The ergometer training was followed by strength and mobilisation training guided by a trained midwife. At the start of the intervention phase the focus was on postnatal and general pelvic floor exercises (c. $15 \mathrm{~min}$ ). In the course of the intervention period, depending on individual performance, general trunk-stabilising exercises (isometric postural exercises, simple coordinated strengthening exercises, mobilisation exercises) were added. Similarly to the ergometer training, the exercise duration was gradually increased from 15 to $30 \mathrm{~min}$. The subjects were responsible for including additional weekly exercise in their daily routine consisting of a brisk walk at an interval of 2 to 3 days. They were asked about this at each exercise date and the answer was documented in the training record. 


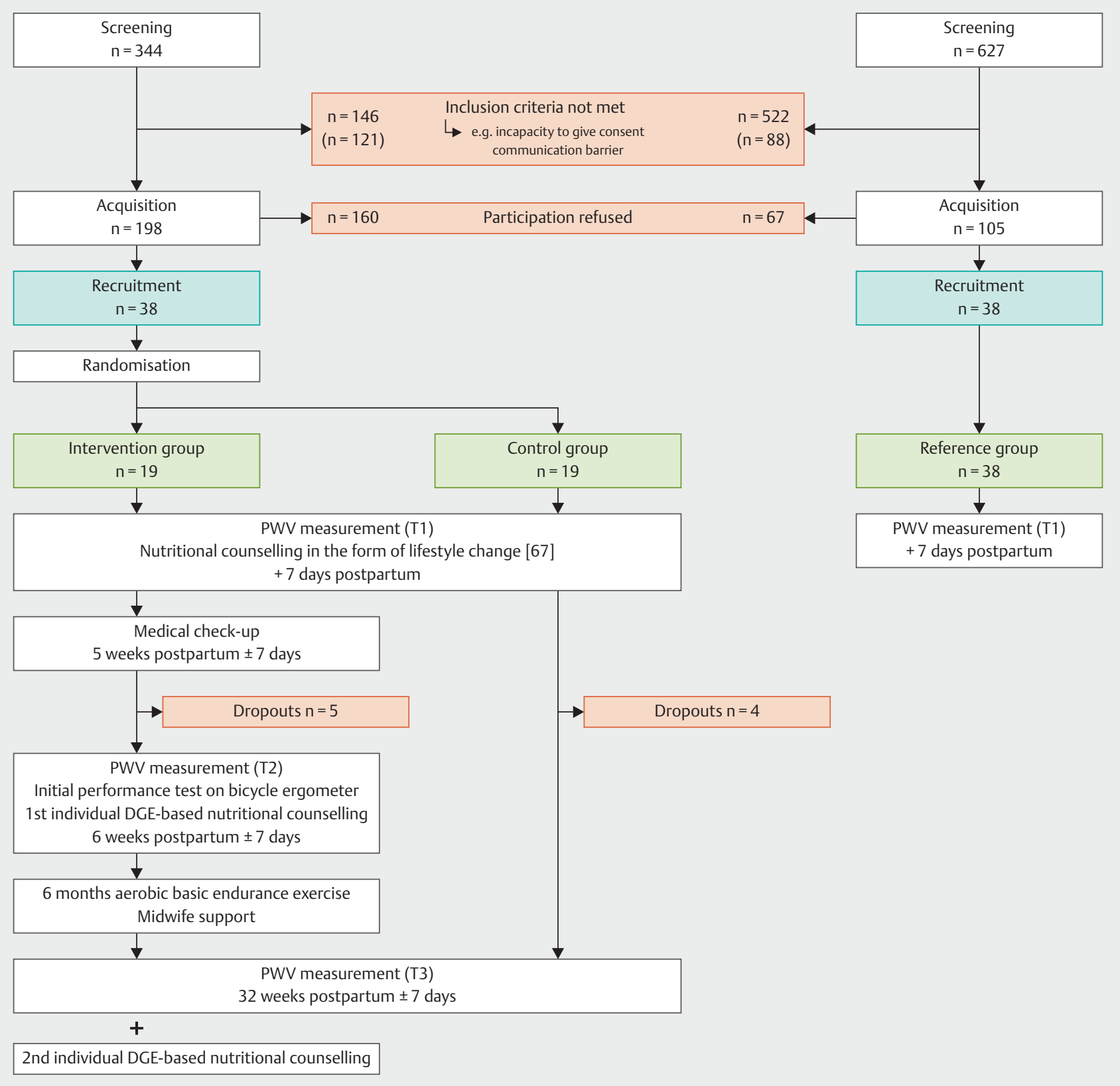

- Fig. 2 Flow chart for the different study phases.

\section{Individual nutritional counselling}

Apart from the risk factors according to the guideline [45], the lifestyle factor "Nutrition" was examined in more detail in the hospital discharge and final interview with all study patients in the intervention and control groups and the treating doctors explained this factor in their counselling. This counselling, based on the 10 nutritional rules of the German Nutrition Society (DGE), concentrated on a Mediterranean diet as well as fat quality, wholegrain products, fruit and vegetable intake and also salt reduction. All patients were also motivated actively in this discussion to change their lifestyle (including regular physical exercise).
The patients in the intervention group also had a second and third individual nutritional counselling session (each of 90120 min, 6 weeks postpartum and 32 weeks postpartum $\rightarrow$ final session). The content of these counselling sessions by a nutritional adviser and qualified dietician certified according to German Nutrition Society regulations consisted of:

- nutritional counselling based on the nutritional rules of the German Nutrition Society (DGE), including the Mediterranean diet as well as fat quality, whole-grain products, fruit and vegetable intake and also salt reduction,

- Medical history (history questionnaire - Society for nutritional therapy and prevention [FET] e.V.), 
- Table 1 Demographic and anthropometric subject characteristics.

\begin{tabular}{|c|c|c|c|c|c|}
\hline Variables & $\begin{array}{l}\text { Intervention group } \\
n=14\end{array}$ & $\begin{array}{l}\text { Control group } \\
n=15\end{array}$ & $\begin{array}{l}\text { Total } \\
n=29\end{array}$ & $\begin{array}{l}\text { Total } \\
\mathrm{n}=38\end{array}$ & \\
\hline Age (years) ${ }^{\circ}$ & $31 \pm 3.89$ & $31 \pm 3.32$ & $31 \pm 4$ & $31 \pm 5$ & \\
\hline Height $(\mathrm{cm})^{\circ}$ & $166 \pm 5.55$ & $167 \pm 7.03$ & $166 \pm 6$ & $168 \pm 7$ & \\
\hline Weight $(\mathrm{kg})^{\circ}$ & $86.3 \pm 14$ & $87.5 \pm 19.5$ & $86.9 \pm 17$ & $82.3 \pm 11$ & \\
\hline Abdominal girth $(\mathrm{cm})^{\circ}$ & $104.2 \pm 9.80$ & $108.1 \pm 16.23$ & $106.3 \pm 14$ & $102.6 \pm 10$ & \\
\hline Thigh circumference $(\mathrm{cm})^{\circ}$ & $61.3 \pm 8.04$ & $62.4 \pm 11.32$ & $61.9 \pm 9.6$ & $57.8 \pm 7.0$ & \\
\hline Systolic BP postpartum (mmHg) & $148 \pm 16$ & $148 \pm 10$ & $148 \pm 13$ & $120 \pm 11$ & $\mathrm{p}<0.01$ \\
\hline Diastolic BP postpartum $(\mathrm{mmHg})^{\circ}$ & $85 \pm 9$ & $84 \pm 9$ & $85 \pm 9$ & $72 \pm 7$ & $\mathrm{p}<0.01$ \\
\hline Delivery (weeks of pregnancy) ${ }^{\circ}$ & $36 \pm 4$ & $35 \pm 5$ & $36 \pm 5$ & $40 \pm 2$ & $\mathrm{p}<0.01$ \\
\hline Birth weight $(g)^{\circ}$ & $2547 \pm 960$ & $2114 \pm 1054$ & $2323 \pm 1016$ & $3505 \pm 513$ & $\mathrm{p}<0.01$ \\
\hline Pre-existing hypertension* & $1(7)$ & $3(20)$ & $4(14)$ & $1(3)$ & \\
\hline Primigravida* & $9(64)$ & $6(40)$ & $15(52)$ & $16(42)$ & \\
\hline Primipara* & $13(93)$ & $10(67)$ & $23(79)$ & $22(58)$ & \\
\hline Multiple pregnancy* & $2(14)$ & $2(13)$ & $4(14)$ & $0(0)$ & $\mathrm{p}<0.05$ \\
\hline Previous infertility treatment* & $4(29)$ & $4(27)$ & $8(28)$ & $0(0)$ & $\mathrm{p}<0.01$ \\
\hline Pathological uterine resistance* & $2(14)$ & $4(27)$ & $6(21)$ & $0(0)$ & $\mathrm{p}<0.01$ \\
\hline IUGR* & $3(21)$ & $6(40)$ & $9(31)$ & $3(8)$ & $\mathrm{p}<0.05$ \\
\hline
\end{tabular}

- Determination of body weight and composition (TANITA ${ }^{\circledR}$ BC545),

- Recording of the nutritional behaviour using a questionnaire (after Winkler 1998) [46].

\section{Feasibility analysis}

To examine the feasibility of the study, adherence with nutritional counselling and the aerobic basic endurance exercise were documented by the study personnel at all contacts. In addition, the subjects were given a direct possibility for feedback through analysis of nutrition and performance tests at the beginning and end of the aerobic basic endurance exercise. In the dropout subjects, the reasons were evaluated and the subjects were asked about this. The subjects were also given the possibility of giving their feedback on the study personally by email at any time during the nutritional counselling sessions, measurements of pulse wave velocity or aerobic basic endurance exercise so as to achieve greater adherence to the study.

In particular, the midwife-supported setting in the context of the exercise, in addition to ensuring qualified care of the baby, was also designed to give the subjects the opportunity of obtaining the midwife's advice on specific topics such as postnatal recovery, breast-feeding or psychosocial questions and problems.

\section{Estimation of case numbers and statistical analysis}

In advance of the pilot study, the case numbers were estimated at the Institute for Medical Epidemiology, Biometrics and Informatics of Martin Luther University Halle-Wittenberg, based on the changes in pulse wave velocity (primary outcome) within 6 months. At a significance level of $p<0.05$, a power (1-beta) of
$80 \%$, a 2-sided t-test and an assumed difference in the mean of $0.90 \mathrm{~m} / \mathrm{s}$ between the healthy population of the same age (pulse wave velocity: $6.35 \mathrm{~m} / \mathrm{s}$ ) and the intervention group after 6 months $(7.25 \mathrm{~m} / \mathrm{s})$, at a given standard deviation of $1.00 \mathrm{~m} / \mathrm{s}$, at least 17 subjects are needed per group, with an expected dropout of $20 \%[47,48]$. Accordingly, 20 subjects would have to be included initially in both groups.

Statistical analysis of the data was performed with SPSS version 25.0 (SPSS Inc., IBM, Armonk, NY, USA). Continuous and categorical variables were shown as mean \pm standard deviation (SD) or as a percentage. Differences in the mean were examined by general linear model. In addition the effect size was calculated according to Hartmann et al. (1992) (difference in the mean divided by the pooled standard deviation of the 2 measurement times [T]) [49]. The interpretation of the effect sizes is based on Cohen's recommendations (1988) [50]. According to this, small effects $(d<0.5)$ must be distinguished from moderate effects $(d<0.8)$ and large effects $(d \geq 0.8)$. Positive effect sizes are interpreted as an increase in performance.

Differences in the mean were interpreted as significant when $\mathrm{p}<0.05$ and $\mathrm{d}>0.5, \eta_{\mathrm{p}}{ }^{2}>0.10$ and the power (observed power) was greater than 0.8 [51].

Relations between metrically scaled variables were examined by means of product-moment correlations (Pearson).

\section{Ethics committee approval}

The study was approved by the ethics committees of the medical faculty of Martin Luther University Halle-Wittenberg and of the Medical Council of Saxony-Anhalt (decision no.: 2015-134) and then registered in ClinicalTrials.gov (identifier: NCT02754778). 


\section{Results}

\section{Subjects}

In the period from May 2016 to April 2018 (24 months) 344 women were screened for the interventional part of the study and 198 women were approached according to the inclusion and exclusion criteria and if adequate communication was possible (acquisition). 38 women gave their consent to take part in the study and were randomised (recruitment) ( $\triangleright$ Table 1 ).

For the reference group, 627 women were screened (the entire birth cohort of both study sites in the period from May 2017 to June 2017). 105 women met the requirements for inclusion in the reference group; these were addressed by the study team (acquisition). 38 of these women were included in the reference group (recruitment).

The reference group of subjects without previous cardiovascular disease or pregnancy complications examined postpartum did not differ significantly from the subjects who had had preeclampsia with or without pre-existing hypertension and/or HELLP syndrome with regard to age $(p=0.850)$, height $(p=0.271)$ and weight $(p=0.496)$. On the other hand, significant differences were observed in birth weight $(p<0.01)$, weeks of pregnancy at delivery $(p<0.01)$ and the rate of intrauterine growth retardation (IUGR) $(p<0.05)$ and section $(p<0.01)$. As expected, significant differences were also found in systolic $(p<0.01)$ and diastolic $(p<0.01)$ blood pressure ( $\triangleright$ Table 1$)$.

The majority of the patients had a form of late-onset preeclampsia appearing after 34 weeks of pregnancy, and there were no significant differences in the frequency of diagnosis between the intervention and control groups ( $\triangleright$ Table 2 ).

The average lowest platelet count $(p=0.971)$ in HELLP syndrome and the average sFlt-1/PIGF ratio $(p=0.956)$ did not differ significantly in these groups ( $\triangleright$ Table 3 ).

\section{Effects and test results}

The postpartum aPWV at T1 showed a marked difference between subjects who had had preeclampsia with or without pre-existing hypertension and/or HELLP syndrome and the healthy reference group ( $\vee$ Fig. 3 ). While the average aPWV of the healthy reference group corresponded to the age class-stratified reference values of the Arterial Stiffness Collaboration Group ( $<30$ years $6.2 \pm 0.75 ; 30-39$ years $6.5 \pm 1.35$ ) [52], significantly higher pulse wave velocity and thus greater vascular age $(6.5$ vs. $7.5 \mathrm{~m} / \mathrm{s}$, $p<0.01$ ) were found in the subjects with prior preeclampsia and/ or HELLP syndrome.

Variance analysis (T1 vs. T3; • Table 4) yielded significant time effects in all parameters when the control and intervention groups were compared, based on the defined criteria of significance $\left(p<0.05\right.$ and $\eta_{p}{ }^{2} \geq 0.10, d \geq 0.50$ and observed power $\geq 0.80$ ), with the exception of the parameters aPWV, pPWV und Alx. Significant group or interaction effects (time $\times$ group) were not observed in this pilot study, probably due to the lack of power and the case number. However, the effect for the parameter aPWV between T1 and T3 was markedly greater in the intervention group than in the control group ( $d=0.90$ vs. $d=0.56)$. The greatest individual effects were found in the intervention group
- Table 2 Frequency distribution with regard to diagnosis and time of diagnosis.

\begin{tabular}{|c|c|c|c|}
\hline & Diagnosis & $\begin{array}{l}\text { Intervention } \\
\text { group } \\
\mathrm{n}=14\end{array}$ & $\begin{array}{l}\text { Control } \\
\text { group } \\
\mathrm{n}=15\end{array}$ \\
\hline \multirow{3}{*}{$\begin{array}{l}>34 \\
\text { weeks }\end{array}$} & Preeclampsia & $7(50)$ & $6(40)$ \\
\hline & $\begin{array}{l}\text { Preeclampsia with pre- } \\
\text { existing hypertension }\end{array}$ & $1(7)$ & $2(13)$ \\
\hline & HELLP syndrome & $3(21)$ & $2(13)$ \\
\hline \multirow{3}{*}{$\begin{array}{l}\leq 34 \\
\text { weeks }\end{array}$} & Preeclampsia & $1(7)$ & $1(7)$ \\
\hline & $\begin{array}{l}\text { Preeclampsia with pre- } \\
\text { existing hypertension }\end{array}$ & $0(0)$ & $1(7)$ \\
\hline & HELLP syndrome & $2(14)$ & $3(20)$ \\
\hline
\end{tabular}

- Table 3 Means of the typical preeclampsia laboratory parameters.

\begin{tabular}{|l|c|c|}
\hline Laboratory parameter & $\begin{array}{l}\text { Intervention group } \\
\mathbf{n = 1 4}\end{array}$ & $\begin{array}{l}\text { Control group } \\
\mathbf{n = 1 5}\end{array}$ \\
\hline $\begin{array}{l}\text { Minimum platelets } \\
\text { (Gpt/l) }\end{array}$ & $77 \pm 45$ & $87 \pm 33$ \\
\hline sFlt-1/PIGF & $223 \pm 199$ & $241 \pm 88$ \\
\hline
\end{tabular}

The data are given as mean (standard deviation).

sFlt-1: soluble Fms-like tyrosine kinase-1; PIGF: placental growth factor

for the parameters mean arterial pressure (MAP) $(d=2.82)$ and systolic blood pressure (syst. BP) $(d=2.52)$ and in the control group for the parameter syst. BP $(d=1.76)$.

There was a high correlation between the achieved exercise frequency and performance at the 2-mmol/l lactate threshold, which acted as an indicator of basic aerobic endurance $(r=0.739)$. Accordingly, the increases in performance $(9.36 \pm 10.8 \mathrm{~W}$; range: -5 to $32 \mathrm{~W})$ were greater in the intervention group the more frequent the exercise ( $\vee$ Fig. 4 ).

\section{Feasibility analysis}

266 out of the total of 364 exercise appointments (73\%) were kept. Each of the 14 subjects in the intervention group took part in at least $50 \%$ of the appointments for exercise training. With regard to the intervention group a statistically $(p=0.013)$ and clinically significant $(d=0.59)$ increase in ergometer performance at the $2-\mathrm{mmol} / \mathrm{l}$ lactate threshold was observed (T1: $51.6 \pm 10.6$ vs. T3: $60.1 \pm 18.1$; - Table 4). Depending on the exercise frequency and intensity (cut-off: $\geq 80 \%, n=7$ ), higher performance in watts was seen at the $2-\mathrm{mmol} / \mathrm{l}$ lactate threshold when the baseline and final tests were compared (difference in the groups: $18 \mathrm{~W}$ vs. $1 \mathrm{~W}$, $p=0.002$ ). Moreover, greater exercise frequency and intensity implied a tendency to lower PWV and thus to decreasing arterial stiffness (6.0 vs. $6.6 \mathrm{~m} / \mathrm{s}, \mathrm{p}=0.099)$. 


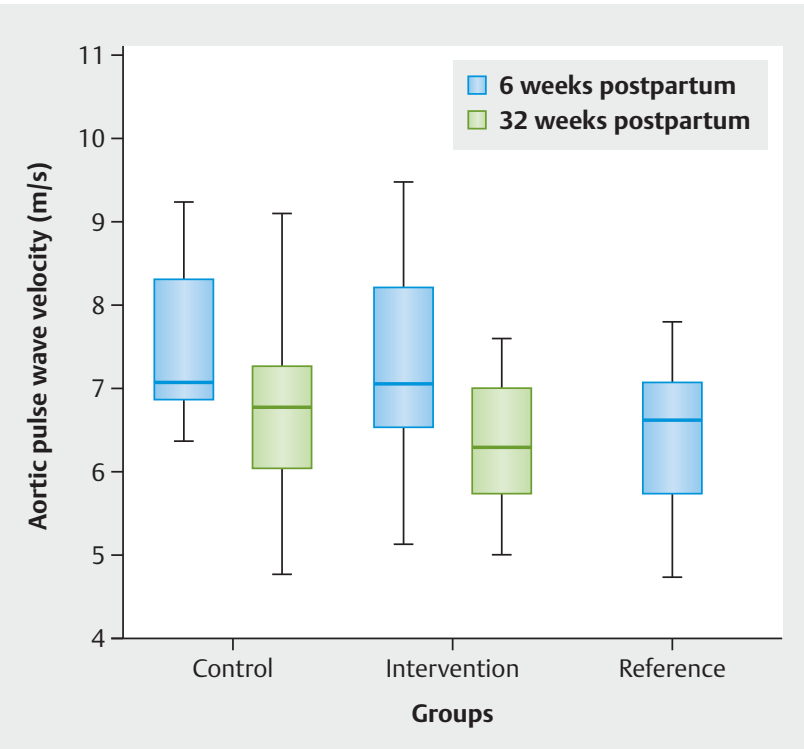

- Fig. 3 Illustration of aortic pulse wave velocity in the study groups at $\mathrm{T} 1$ and $\mathrm{T} 3$.

All patients availed of the postpartum nutritional counselling in the form of lifestyle changes advised by the study doctors when patients were recruited to the study and on hospital discharge. Only 11 subjects in the intervention group took part 6 weeks postpartum in the first individual DGE-based nutritional counselling session with nutritional analysis, which was conducted by a certified dietitian. 22 of the 28 appointments (79\%) for individual DGEbased nutritional counselling (excluding the nutritional counselling in the form of advice on lifestyle changes on recruitment to the study) were kept. Patients who attended both DGE-based nutritional counselling session performed 10 watts more on average on the bicycle ergometer at the conclusion of the intervention than those who had taken part only in the nutritional counselling in the form of lifestyle change advised on the occasion of hospital discharge ( 14 vs. $4 \mathrm{~W}, \mathrm{p}=0.04$ ). Lower aPWV and therefore improved arterial stiffness were also seen in patients who had two individual DGE-based nutritional counselling sessions compared with only one session (6.1 vs. $6.7 \mathrm{~m} / \mathrm{s}, \mathrm{p}=0.06$ ).

\section{Dropouts}

A total of 5 subjects in the intervention group and 4 subjects in the control group dropped out of the study on their own motivation in all cases. While dealing with grief because of the postpartum death of the baby was the main reason for dropping out in one case, there were organisational or structural problems (physical distance, excessive demands with the child, language and cultural barrier) including in motivation in the other 8 cases. No dropout was indicated medically. All dropouts occurred between 6 weeks and 32 weeks postpartum.

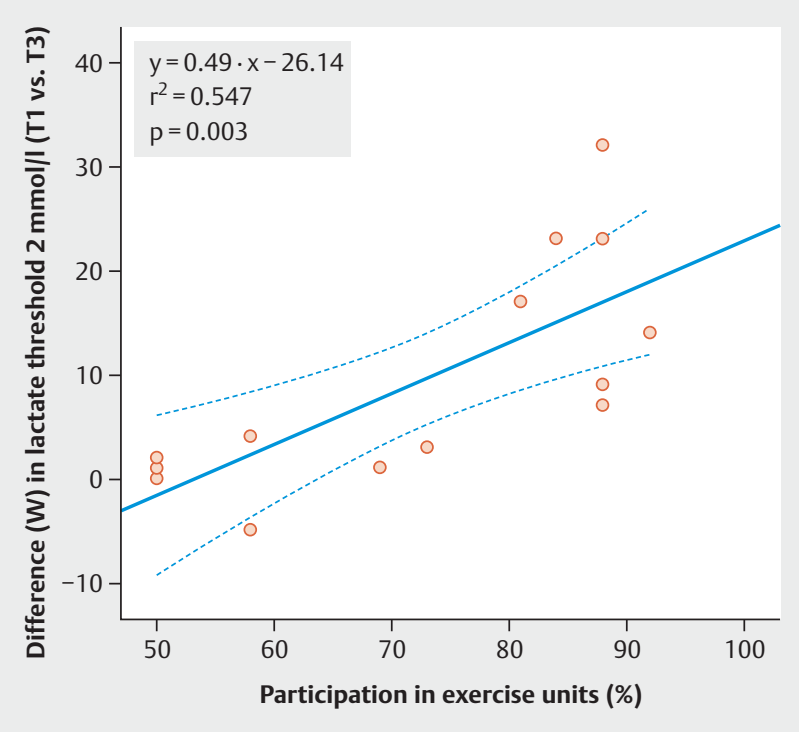

- Fig. 4 Relationship between exercise frequency and the increase in performance achieved at a lactate threshold of $2 \mathrm{mmol} / \mathrm{l}$.

\section{Discussion}

The increasing incidence of preeclampsia in western industrial nations (including because of the steadily increasing average age of pregnant women), increased life expectancy and consequently the sequelae of preeclampsia for lifelong cardiovascular risk are important reasons for focussing scientific research on the secondary and tertiary prophylaxis of cardiovascular events after preeclampsia [6,53-56]. The "window to future health" within pregnancy - acting like a cardiac stress test - makes possible secondary prevention if indicated of cardiovascular disease in women who have had hypertensive disorders of pregnancy such as preeclampsia and HELLP syndrome.

An important difficulty in secondary and tertiary prophylaxis is represented by the apparent recovery of a majority of patients who feel hardly any symptoms at the end of the postpartum period and who are also liable to be distracted from their own health because of caring for their infant, with the change in their role from that of a pregnant woman to that of a mother. In reality, only about a quarter of women who have had preeclampsia are prepared to take part in an additional exercise/sport unit at least once a week if it is left up to them (surveyed 6 months postpartum) [57]. In addition, it was apparent that 27 of 78 surveyed patients did sport less frequently after the index event (preeclampsia) than before the pregnancy (increase in frequency in only 6 of 78 patients). Available studies show that unaffected women can be motivated to more physical activity by convincing information about health aspects [58]. In this study, in addition to consistent advice in the pre-discharge discussion with these patients, involvement of a midwife in the exercise setting subsequently laid an effective foundation for good adherence of the subjects to the aerobic basic endurance exercise. Ensuring care of the newborn baby and the possibility of discussing delivery-related problems with the 


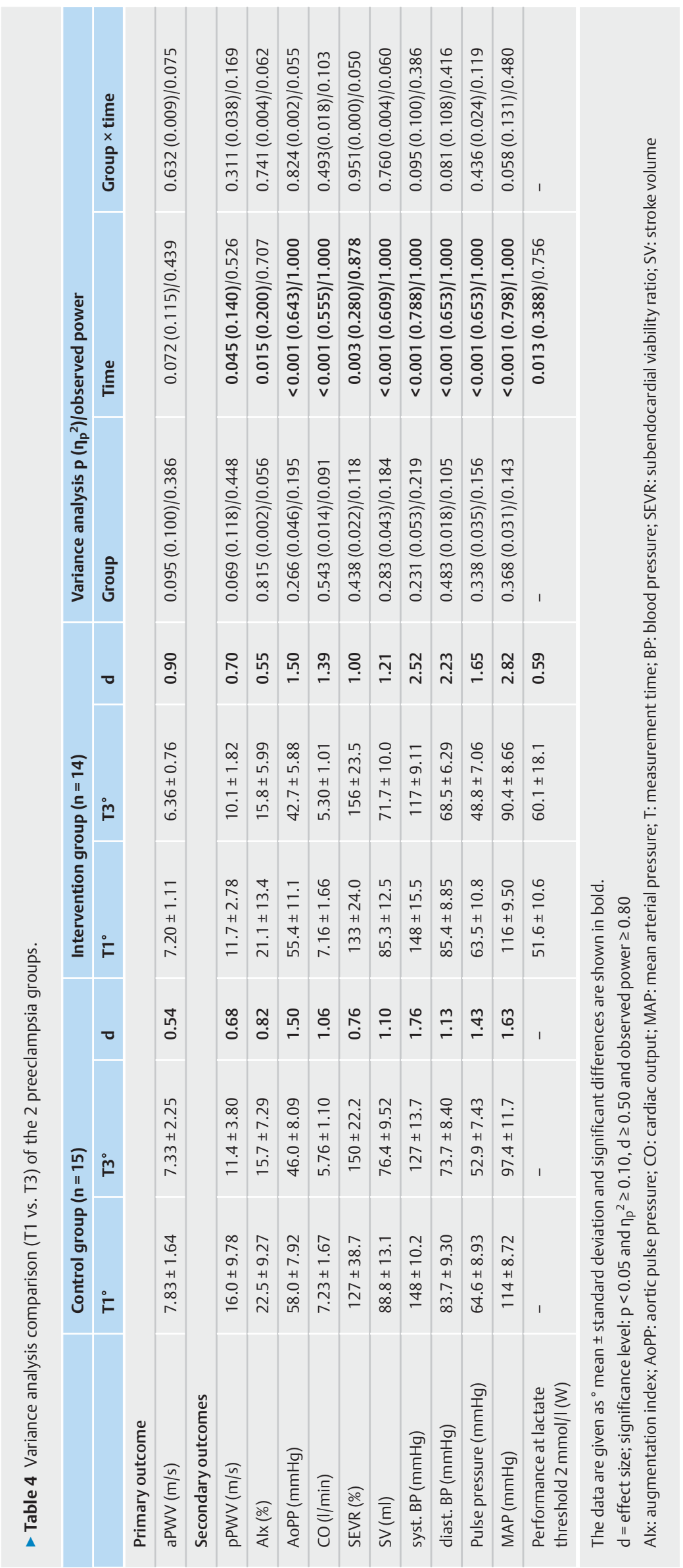


midwife thus acted as a reassuring factor. In future studies to confirm the results of this study, inclusion of such an exercise programme in midwives' clinics in conjunction with postnatal exercise classes is worth considering for women who have had hypertensive disorders of pregnancy and could further enhance the already considerable value of the midwives beyond delivery, for instance with regard to subsequent pregnancies. The psychosocial peer group contacts that take place in these postnatal classes are also of value. Socioeconomic aspects can be latent reasons for a) lack of exercise compliance and b) for rejection of general lifestyle changes and should be investigated in detail. Future studies should therefore focus, among other things, on the evaluation of reasons for dropping out of the study and also on the development of alternative possibilities for patients who cannot follow the exercise training because of exclusion criteria. Only in this way can secondary and tertiary prevention concepts be devised that also offer solutions for women in precarious social or familial situations.

A high level of intrinsic patient motivation also remains crucial, and this is inevitably linked with the care and current health of the baby and sometimes multiple babies or when she already has older children to care for.

This study in a group of women who had had severe hypertensive disorders of pregnancy (preeclampsia with or without previous hypertension and/or HELLP syndrome) showed for the first time that:

- There is a high level of willingness to take part actively in aerobic basic endurance exercise in conjunction with nutritional counselling,

- Aerobic basic endurance exercise (intervention) can reduce arterial stiffness as a biomarker for the risk of cardiovascular disease.

In the control group, a biological vascular age corresponding to that of the healthy population at least 10 years older was shown 32 weeks after delivery, while the subjects in the intervention group showed a pulse wave velocity corresponding to the biological vascular age of the healthy population of the same age (comparison in $>$ Table 4 and reference values [52]). An increase in PWV of $1 \mathrm{~m} / \mathrm{s}$ corresponds to a risk increase of $15 \%$ for cardiovascular morbidity and events [59].

The results of this pilot study confirm the hypothesis of the short- and medium-term effect of a regular exercise intervention to reduce vascular stiffness and hence the cardiovascular risk at least to the level of the healthy population of the same age following preeclampsia with or without previous hypertension and/or HELLP syndrome. Nevertheless, the success of the intervention appears to depend crucially on starting promptly after the end of the puerperium and continuing for at least 6 months as, by contrast, Scholten et al. [14] with a similar intervention for only 12 weeks starting 6 months postpartum were unable to show any improvement in the vascular status of women with previous preeclampsia.

If the preventive effects of the aerobic basic endurance exercise are perpetuated, women in the intervention group would not develop cardiovascular disease or, if they did, would at least do so much later. This would result in a gain for the overall popu- lation from the health and economic points of view. For instance, estimates of the annual costs of disease and absence from work due to lack of exercise and the resulting cardiovascular disease in Germany alone amount to up to 21 billion Euro [60,61].

The results are an impetus to initiate a larger multicentre, randomised, complex interventional study, which should also look at an evaluation of other risk factors/biomarkers in addition to standardising the sports and nutritional medicine setting. Only a longterm follow-up study can confirm the improved outcome, similar to the Framingham study.

Applying the results to the standard care of women with preeclampsia with or without previous hypertension and/or HELLP syndrome requires calculations of cost-effectiveness, which take into account, on the one hand, how much the exercise units cost and the adherence of the participating women and, on the other hand, what reduction in morbidity can be expected and how much can be saved from the cost of treating cardiovascular disease.

The results are limited by a high dropout rate (24\%). As regards the high dropout rate, based on the justified reasons given by the subjects, the possibility of taking part in basic aerobic endurance training, nutritional counselling, medical diagnostics and health education close to home should be considered in further studies.

Studies also confirm that a healthy diet, as promoted in a lifestyle intervention, is associated with higher costs and hence with socioeconomic status [62-64]. Socioeconomic reasons are therefore also decisive for participation in an exercise programme and for switching diet. Their importance and thus the underlying dropouts must be recorded more intensively in future so that an equal-opportunity risk reduction can be achieved, independent of socioeconomic status.

As regards the achieved exercise effects, especially with reference to the non-significant interaction effects, adaptation of the load parameters of the exercise intervention should be considered and the exercise should be intensified if appropriate. Because of a lack of evidence and out of ethical considerations, a comparatively moderate exercise programme was conceived initially.

The reduction in pulse wave velocity in the control group $(d=0.54)$ corresponds to the physiological effect and must be included in the interpretation of the effect in the intervention group. Morris et al. showed that there was a physiological reduction in arterial stiffness in normotensive women to pre-conception levels 14 months postpartum [65]. Yuan et al. [60] also demonstrated this 20 months postpartum in large arteries and described remodelling of the carotid artery in pregnancy and recovery in the postpartum period. Mersich et al. [61] found a physiological reduction in arterial stiffness both in normotensive women and in women with preeclampsia 3 months postpartum compared with the 3rd trimester. Foo et al. [62] observed this effect as a partial remission of endothelial dysfunction. However, women with disease did not reach pre-pregnancy levels [66]. In a 10year follow-up increased arterial stiffness was found in the previously hypertensive pregnant women compared with the healthy reference group [30]. Reference levels of the general physiological reduction in arterial stiffness after pregnancy with and without hypertensive disorders of pregnancy must also be the basis in further studies for evaluating individual targeted exercise [67]. 
The validity of this study is limited by the small case number, which is too low to allow conclusions about influencing factors such as pre-existing hypertension, IUGR, multiple pregnancies and previous infertility treatments, which were represented heterogeneously in the intervention and control groups. Subgroup analyses were not possible but would have to be planned in subsequent studies with larger case numbers. The influence of preexisting hypertension, in particular, should be studied separately as a cardiovascular risk factor involving pre-existing vascular modelling, as the pathogenesis of superimposed preeclampsia is possibly altered. With this diagnosis, pre-conception lifestyle intervention might very probably be more effective in influencing arterial stiffness than postpartum intervention. The absence of a risk reduction for IUGR and superimposed preeclampsia when aspirin is taken in accordance with guidelines (starting $<16$ weeks) in women with pre-existing hypertension appears to support the hypothesis [68].

\section{Conclusion}

The study confirms the feasibility and the great importance of lifestyle intervention with aerobic basic endurance exercise starting 6 weeks postpartum. The intervention shows a significant clinical effect by reducing arterial stiffness to the level of the general population. An optimal setting in an interdisciplinary team that includes varied midwife-supported care (incl. pelvic floor exercises, psychosocial support) beyond childbirth appears decisive for good adherence and the associated success of cardiovascular risk reduction as well as timely intervention for at least 6 months.

Before this intervention can be included in the standard of care and prevention, follow-up studies must confirm these results and the medium-term effects on cardiovascular risk.

ClinicalTrials.gov Identifier: NCT02754778

\section{Acknowledgements}

Particular thanks to midwives Julia Böhme, Marie Bastian, Franziska Bremer, Hedwig Weiher and medical student Christin Descher for their generous assistance during the intervention and to Prof. Andreas Wienke for his statistical advice.

\section{Conflict of Interest}

The authors declare that they have no conflict of interest.

References

[1] Umesawa M, Kobashi G. Epidemiology of hypertensive disorders in pregnancy: prevalence, risk factors, predictors and prognosis. Hypertens Res 2017; 40: 213-220. doi:10.1038/hr.2016.126

[2] Kuklina EV, Ayala C, Callaghan WM. Hypertensive disorders and severe obstetric morbidity in the United States. Obstet Gynecol 2009; 113: 1299-1306. doi:10.1097/AOG.0b013e3181a45b25

[3] Khan KS, Wojdyla D, Say L et al. WHO analysis of causes of maternal death: a systematic review. Lancet 2006; 367: 1066-1074. doi:10.1016/S0140-6736(06)68397-9
[4] Say L, Chou D, Gemmill A et al. Global causes of maternal death: a WHO systematic analysis. Lancet Glob Health 2014; 2: e323-e333. doi:10.1016/S2214-109X(14)70227-X

[5] Vogel JP, Souza JP, Mori R et al. Maternal complications and perinata mortality: findings of the World Health Organization Multicountry Survey on Maternal and Newborn Health. BJOG 2014; 121 (Suppl. 1): 7688. doi:10.1111/1471-0528.12633

[6] Wu P, Haththotuwa R, Kwok CS et al. Preeclampsia and Future Cardiovascular Health: A Systematic Review and Meta-Analysis. Circ Cardiovasc Qual Outcomes 2017. doi:10.1161/CIRCOUTCOMES.116.003497

[7] Leon LJ, McCarthy FP, Direk K et al. Preeclampsia and Cardiovascular Disease in a Large UK Pregnancy Cohort of Linked Electronic Health Records: A CALIBER Study. Circulation 2019; 140: 1050-1060. doi:10.1161/CIRCULATIONAHA. 118.038080

[8] Vikse BE, Irgens LM, Leivestad T et al. Preeclampsia and the risk of endstage renal disease. N Engl ] Med 2008; 359: 800-809. doi:10.1056/ NEJMoa0706790

[9] Vikse BE, Hallan S, Bostad L et al. Previous preeclampsia and risk for progression of biopsy-verified kidney disease to end-stage renal disease. Nephrol Dial Transplant 2010; 25: 3289-3296. doi:10.1093/ndt/gfq169

[10] Naghavi M, Abajobir AA, Abbafati C et al. Global, regional, and national age-sex specific mortality for 264 causes of death, 1980-2016: a systematic analysis for the Global Burden of Disease Study 2016. Lancet 2017; 390: 1151-1210. doi:10.1016/S0140-6736(17)32152-9

[11] destatis. Herz-Kreislauf-Erkrankungen verursachen die höchsten Kosten (September 2017). Accessed April 06, 2020 at: https://www.destatis.de/ DE/Presse/Pressemitteilungen/2017/09/PD17_347_236.html

[12] destatis. Zahl der Todesfälle im Jahr 2015 um 6,5\% gestiegen (Januar 2017). Accessed April 06, 2020 at: www.destatis.de/DE/Presse/ Pressemitteilungen/2017/01/PD17_022_232.html

[13] Deharde D, Klockenbusch W, Schmitz R et al. Hydroxychloroquine as a Preventive and Therapeutic Option in Preeclampsia - a Literature Review. Geburtshilfe Frauenheilkd 2020; 80: 679-685. doi:10.1055/ a-1170-5145

[14] Scholten RR, Thijssen DJ, Lotgering FK et al. Cardiovascular effects of aerobic exercise training in formerly preeclamptic women and healthy parous control subjects. Am J Obstet Gynecol 2014; 211: 516.e1-516.e11. doi:10.1016/j.ajog.2014.04.025

[15] Hu FB, Stampfer MJ, Solomon C et al. Physical activity and risk for cardiovascular events in diabetic women. Ann Intern Med 2001; 134: 96-105

[16] Giroir BP, Wright D. Physical Activity Guidelines for Health and Prosperity in the United States. JAMA 2018; 320: 1971-1972. doi:10.1001/ jama.2018.16998

[17] Piepoli MF, Hoes AW, Agewall S et al. 2016 European Guidelines on cardiovascular disease prevention in clinical practice: The Sixth Joint Task Force of the European Society of Cardiology and Other Societies on Cardiovascular Disease Prevention in Clinical Practice (constituted by representatives of 10 societies and by invited experts) Developed with the special contribution of the European Association for Cardiovascular Prevention \& Rehabilitation (EACPR). Eur Heart J 2016; 37: 2315-2381. doi:10.1093/eurheartj/ehw106

[18] Cupples ME, McKnight A. Randomised controlled trial of health promotion in general practice for patients at high cardiovascular risk. BM] 1994; 309: 993-996. doi:10.1136/bmj.309.6960.993

[19] World Health Organization. Diet, Nutrition, and the Prevention of Chronic Diseases: Report of a Joint WHO/FAO Expert Consultation. Geneva: World Health Organization; 2003

[20] Badimon L, Chagas P, Chiva-Blanch G. Diet and Cardiovascular Disease: Effects of Foods and Nutrients in Classical and Emerging Cardiovascular Risk Factors. Curr Med Chem 2019; 26: 3639-3651. doi:10.2174/ 0929867324666170428103206 
[21] Ros E, Martinez-Gonzalez MA, Estruch R et al. Mediterranean diet and cardiovascular health: Teachings of the PREDIMED study. Adv Nutr 2014; 5: 330S-336S. doi:10.3945/an.113.005389

[22] Enkhmaa D, Wall D, Mehta PK et al. Preeclampsia and Vascular Function: A Window to Future Cardiovascular Disease Risk. J Womens Health (Larchmt) 2016; 25: 284-291. doi:10.1089/jwh.2015.5414

[23] Cain MA, Salemi JL, Tanner JP et al. Pregnancy as a window to future health: maternal placental syndromes and short-term cardiovascular outcomes. Am J Obstet Gynecol 2016; 215: 484.e1-484.e14. doi:10.1016/j.ajog.2016.05.047

[24] Gilmore LA, Klempel-Donchenko M, Redman LM. Pregnancy as a window to future health: Excessive gestational weight gain and obesity. Semin Perinatol 2015; 39: 296-303. doi:10.1053/j.semperi.2015.05.009

[25] Catov JM, Margerison-Zilko C. Pregnancy as a window to future health: short-term costs and consequences. Am J Obstet Gynecol 2016; 215: 406-407. doi:10.1016/j.ajog.2016.06.060

[26] Sander GE, Giles TD. Vascular stiffness is a biomarker of global cardiovascular risk. J Clin Hypertens (Greenwich) 2014; 16: 625-626. doi:10.1111/jch. 12380

[27] Zieman SJ, Melenovsky V, Kass DA. Mechanisms, pathophysiology, and therapy of arterial stiffness. Arterioscler Thromb Vasc Biol 2005; 25: 932-943. doi:10.1161/01.ATV.0000160548.78317.29

[28] Foo FL, McEniery CM, Lees C et al. Assessment of arterial function in pregnancy: recommendations of the International Working Group on Maternal Hemodynamics. Ultrasound Obstet Gynecol 2017; 50: 324331. doi:10.1002/uog. 17565

[29] Elvan-Taspinar A, Bots ML, Franx A et al. Stiffness of the arterial wall, joints and skin in women with a history of pre-eclampsia. J Hypertens 2005; 23: 147-151. doi:10.1097/00004872-200501000-00025

[30] Christensen M, Kronborg CJs, Knudsen UB. Preeclampsia and arterial stiffness - A 10-year follow up of previous preeclamptic women. Pregnancy Hypertension: An International Journal of Women's Cardiovascular Health 2015; 5: 72-73. doi:10.1016/j.preghy.2014.10.145

[31] Rath W, Tsikouras P, Stelzl P. HELLP Syndrome or Acute Fatty Liver of Pregnancy: A Differential Diagnostic Challenge: Common Features and Differences. Geburtshilfe Frauenheilkd 2020; 80: 499-507. doi:10.1055/a-1091-8630

[32] Stepan H, Kuse-Föhl S, Klockenbusch W et al. Diagnosis and Treatment of Hypertensive Pregnancy Disorders. Guideline of DGGG (S1-Level, AWMF Registry No.015/018, December 2013). Geburtshilfe Frauenheilkd 2015; 75: 900-914. doi:10.1055/s-0035-1557924

[33] Pucci G, Cheriyan J, Hubsch A et al. Evaluation of the Vicorder, a novel cuff-based device for the noninvasive estimation of central blood pressure. J Hypertens 2013; 31: 77-85. doi:10.1097/HJH.0b013e32835a $8 \mathrm{eb} 1$

[34] Davies JM, Bailey MA, Griffin KJ et al. Pulse wave velocity and the non-invasive methods used to assess it: Complior, SphygmoCor, Arteriograph and Vicorder. Vascular 2012; 20: 342-349. doi:10.1258/vasc.2011. ra0054

[35] Shahin Y, Barakat H, Barnes R et al. The Vicorder device compared with SphygmoCor in the assessment of carotid-femoral pulse wave velocity in patients with peripheral arterial disease. Hypertens Res 2013; 36: $208-$ 212. doi:10.1038/hr.2012.144

[36] Parikh JD, Hollingsworth KG, Kunadian V et al. Measurement of pulse wave velocity in normal ageing: comparison of Vicorder and magnetic resonance phase contrast imaging. BMC Cardiovasc Disord 2016; 16: 50. doi:10.1186/s12872-016-0224-4

[37] Hickson SS, Butlin M, Broad J et al. Validity and repeatability of the Vicorder apparatus: a comparison with the SphygmoCor device. Hypertens Res 2009; 32: 1079-1085. doi:10.1038/hr.2009.154
[38] Chan D, Beska B, Gu S et al. 161 The association of non-invasive cardiovascular parameters on adverse outcomes in older patients following non-ST elevation acute coronary syndrome undergoing invasive care. Heart 2019; 105: A134-A135. doi:10.1136/heartjnl-2019-BCS.158

[39] Kis E, Cseprekál O, Kerti A et al. Measurement of pulse wave velocity in children and young adults: a comparative study using three different devices. Hypertension Research 2011; 34: 1197-1202. doi:10.1038/ hr.2011.103

[40] Kracht D, Shroff R, Baig S et al. Validating a New Oscillometric Device for Aortic Pulse Wave Velocity Measurements in Children and Adolescents. Am J Hypertens 2011; 24: 1294-1299. doi:10.1038/ajh.2011.147

[41] Redheuil A, Bensalah M, Kachenoura N et al. Measuring aortic distensibility with cmr using central pressures estimated in the magnet: comparison with carotid and peripheral pressures. J Cardiovasc Magn Reson 2011; 13: P27. doi:10.1186/1532-429X-13-S1-P27

[42] Pucci G, Cheriyan J, Hubsch A et al. A comparison of the Vicorder apparatus with SphygmoCor device for the non-invasive assessment of aortic blood pressure: an invasive validation study. Artery Research 2010; 4: 146-146. doi:10.1016/j.artres.2010.10.167

[43] Skidmore Medical Limited. Präsentation „Vicorder(C) - Arterielle Steifigkeit - PWV - PWA“. 2009-2011

[44] Dickhuth HH, Huonker M, Münzel T, Drexler H, Berg A, Keul J. Individual Anaerobic Threshold for Evaluation of Competitive Athletes and Patients with Left Ventricular Dysfunction. In: Bachl N, Graham TE, Löllgen H, eds. Advances in Ergometry. Berlin, Heidelberg: Springer; 1991. doi:10.1007| 978-3-642-76442-4_26

[45] Deutsche Gesellschaft für Gynäkologie und Geburtshilfe. S1-Leitlinie: Diagnostik und Therapie hypertensiver Schwangerschaftserkrankungen. 2013. Accessed December 16, 2020 at: https://präeklampsie-hellp.de/ source/Infotexte/015-018I_S1_Diagnostik_Therapie_hypertensiver_ Schwangerschaftserkrankungen_2014-01-1.pdf

[46] Winkler G, Doring A. Validation of a short qualitative food frequency list used in several German large scale surveys. Z Ernahrungswiss 1998; 37 : 234-241. doi:10.1007/pl00007377

[47] Kaihura C, Savvidou MD, Anderson JM et al. Maternal arterial stiffness in pregnancies affected by preeclampsia. Am J Physiol Heart Circ Physiol 2009; 297: H759-H764. doi:10.1152/ajpheart.01106.2008

[48] Ashor AW, Lara J, Siervo M et al. Effects of Exercise Modalities on Arterial Stiffness and Wave Reflection: A Systematic Review and Meta-Analysis of Randomized Controlled Trials. PLoS One 2014; 9: e110034. doi:10.1371/ journal.pone.0110034

[49] Hartmann A, Herzog T, Drinkmann A. Psychotherapy of bulimia nervosa: what is effective? A meta-analysis. J Psychosom Res 1992; 36: 159-167. doi:10.1016/0022-3999(92)90024-v

[50] Cohen J. Statistical Power Analysis for the Behavioral Sciences. New York: Taylor \& Francis; 2013

[51] Richardson JTE. Eta squared and partial eta squared as measures of effect size in educational research. Educational Research Review 2011; 6: 135147. doi:10.1016/j.edurev.2010.12.001

[52] Reference Values for Arterial Stiffness' Collaboration. Determinants of pulse wave velocity in healthy people and in the presence of cardiovascular risk factors: ‘establishing normal and reference values'. Eur Heart ] 2010; 31: 2338-2350. doi:10.1093/eurheartj/ehq165

[53] Wallis AB, Saftlas AF, Hsia J et al. Secular trends in the rates of preeclampsia, eclampsia, and gestational hypertension, United States, 19872004. Am J Hypertens 2008; 21: 521-526. doi:10.1038/ajh.2008.20

[54] Kontis V, Bennett JE, Mathers CD et al. Future life expectancy in 35 industrialised countries: projections with a Bayesian model ensemble. Lancet 2017; 389: 1323-1335. doi:10.1016/s0140-6736(16)32381-9

[55] Honigberg MC, Zekavat SM, Aragam K et al. Long-Term Cardiovascular Risk in Women With Hypertension During Pregnancy. J Am Coll Cardiol 2019; 74: 2743-2754. doi:10.1016/j.jacc.2019.09.052 
[56] Schildberger B, Linzner D, Hehenberger L et al. Influence of Maternal Age on Selected Obstetric Parameters. Geburtshilfe Frauenheilkd 2019; 79: 1208-1215. doi:10.1055/a-0859-0826

[57] Viana Pinto P, Rei M, Machado AP et al. Preeclampsia and future cardiovascular risk: are women and general practitioners aware of this relationship? The experience from a portuguese centre. Obstet Gynecol Int 2014; 2014: 531539. doi:10.1155/2014/531539

[58] Gaston A, Gammage KL. The effectiveness of a health-based message on pregnant women's intentions to exercise postpartum. J Reprod Infant Psychol 2011; 29: 162-169. doi:10.1080/02646838.2010.541230

[59] Vlachopoulos C, Aznaouridis K, Stefanadis C. Prediction of cardiovascular events and all-cause mortality with arterial stiffness: a systematic review and meta-analysis. J Am Coll Cardiol 2010; 55: 1318-1327. doi:10.1016/ j.jacc.2009.10.061

[60] Sjöström M, Oja P, Hagströmer M et al. Health-enhancing physical activity across European Union countries: the Eurobarometer study. J Public Health 2006; 14: 291-300. doi:10.1007/s10389-006-0031-y

[61] DSSV-Arbeitgeberverband deutscher Fitness- und Gesundheits-Anlagen. Körperliche Aktivität senkt Gesundheitsausgaben um ca. 21 Mrd. EUR (Februar 2017). Accessed June 12, 2020 at: https://www.dssv.de/

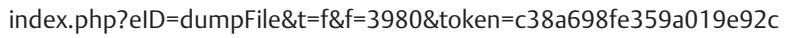
$62 \mathrm{acfb} 5 \mathrm{~d} 560433 \mathrm{e} 78435$

[62] Jones NRV, Conklin Al, Suhrcke M et al. The Growing Price Gap between More and Less Healthy Foods: Analysis of a Novel Longitudinal UK Dataset. PLoS One 2014; 9: e109343. doi:10.1371/journal.pone.0109343
[63] Silva LM, Coolman M, Steegers EA et al. Low socioeconomic status is a risk factor for preeclampsia: the Generation R Study. J Hypertens 2008; 26: 1200-1208. doi:10.1097/HJH.0b013e3282fcc36e

[64] Müller M], Landsberg B, Plachta-Danielzik S et al. Soziale Ungleichheit im Übergewicht. Adipositas - Ursachen, Folgeerkrankungen, Therapie 2009; 03: 88-96. doi:10.1055/s-0037-1618667

[65] Morris EA, Hale SA, Badger G] et al. Pregnancy induces persistent changes in vascular compliance in primiparous women. Am J Obstet Gynecol 2015; 212: 633.e1-633.e6. doi:10.1016/j.ajog.2015.01.005

[66] Foo FL, McEniery CM, Lees C et al. Assessment of arterial function in pregnancy: recommendations of the International Working Group on Maternal Hemodynamics. Ultrasound Obstet Gynecol 2017; 50: 324331. doi:10.1002/uog.17565

[67] Kalapotharakos G, Salehi D, Steding-Ehrenborg K et al. Cardiovascular effects of severe late-onset preeclampsia are reversed within six months postpartum. Pregnancy Hypertens 2020; 19: 18-24. doi:10.1016/ j.preghy.2019.12.005

[68] Banala C, Moreno S, Cruz Y et al. Impact of the ACOG guideline regarding low-dose aspirin for prevention of superimposed preeclampsia in women with chronic hypertension. Am J Obstet Gynecol 2020; 223: 419.e1419.e16. doi:10.1016/j.ajog.2020.03.004 